Research Paper

\title{
Active-target $\mathrm{T}_{1}$-weighted MR Imaging of Tiny Hepatic Tumor via RGD Modified Ultra-small $\mathrm{Fe}_{3} \mathrm{O}_{4}$ Nanoprobes
}

\author{
Zhengyang Jia1 ${ }^{,}$, Lina Song1, ${ }^{*}$, Fengchao Zang ${ }^{2}$, Jiacheng Song ${ }^{3}$, Wei Zhang1, Changzhi Yan ${ }^{1}$, Jun Xie ${ }^{1}$, \\ Zhanlong $\mathrm{Ma}^{3}$, Ming Ma1, Gaojun Teng ${ }^{2}$, Ning Gu${ }^{1,}{ }^{\bowtie}$ and Yu Zhang1, ${ }^{1,}$ \\ 1. State Key Laboratory of Bioelectronics, Jiangsu Key Laboratory for Biomaterials and Devices, School of Biological Science and Medical Engineering \& \\ Collaborative Innovation Center of Suzhou Nano Science and Technology, Southeast University, Nanjing 210096, China \\ 2. Jiangsu Key Laboratory of Molecular and Functional Imaging, Medical School, Southeast University, Nanjing 210009, China \\ 3. Department of Radiology, The First Affiliated Hospital of Nanjing Medical University, Nanjing 210029, China \\ * These authors contributed equally to this work. \\ $\bowtie$ Corresponding author: Yu Zhang, E-mail: zhangyu@seu.edu.cn. Tel: +86 258327 2496. Fax: +86 2583272496
}

(1) Ivyspring International Publisher. Reproduction is permitted for personal, noncommercial use, provided that the article is in whole, unmodified, and properly cited. See http://ivyspring.com/terms for terms and conditions.

Received: 2015.11.01; Accepted: 2016.05.31; Published: 2016.07.15

\begin{abstract}
Developing ultrasensitive contrast agents for the early detection of malignant tumors in liver is highly demanded. Constructing hepatic tumors specific targeting probes could provide more sensitive imaging information but still faces great challenges. Here we report a novel approach for the synthesis of ultra-small $\mathrm{Fe}_{3} \mathrm{O}_{4}$ nanoparticles conjugated with $\mathrm{c}(\mathrm{RGDyK})$ and their applications as active-target $\mathrm{T}_{1}$-weighted magnetic resonance imaging (MRI) contrast agent $\left(\mathrm{T}_{1}-\mathrm{Fe}_{3} \mathrm{O}_{4}\right)$ for imaging tiny hepatic tumors in vivo. RGD-modified $\mathrm{T}_{1}-\mathrm{Fe}_{3} \mathrm{O}_{4}$ nanoprobes exhibited high $r_{1}$ of $7.74 \mathrm{mM}^{-1} \mathrm{~s}^{-1}$ and ultralow $r_{2} / r_{1}$ of 2.8 at $3 \mathrm{~T}$, reflecting their excellent $\mathrm{T}_{1}$ contrast effect at clinically relevant magnetic field. High targeting specificity together with favorable biocompatibility and strong ability to resist against non-specific uptake were evaluated through in vitro studies. Owing to the outstanding properties of tumor angiogenesis targeting with little phagocytosis in liver parenchyma, hepatic tumor as small as 2.2 $\mathrm{mm}$ was successfully detected via the $\mathrm{T}_{1}$ contrast enhancement of RGD-modified $\mathrm{T}_{1}-\mathrm{Fe}_{3} \mathrm{O}_{4}$. It is emphasized that this is the first report on active-target $T_{1}$ imaging of hepatic tumors, which could not only significantly improve diagnostic sensitivity, but also provide post therapeutic assessments for patients with liver cancer.
\end{abstract}

Key words: $\mathrm{T}_{1}-\mathrm{Fe}_{3} \mathrm{O}_{4}$ nanoprobes; RGD-modified; active-target; tiny hepatic tumor imaging; high diagnostic sensitivity

\section{Introduction}

Liver is a frequent region of tumorigenesis and metastases owing to its well-vascularized tissue and accessible capillaries with low blood flow shear rates.[1] Across all cancer types, liver cancer was one of the most frequently diagnosed cancers among men, and it was the second leading cause of cancer deaths worldwide in 2012.[2] The use of early-stage diagnosis, which has implications for patients treatment and prognosis, is an effective strategy to prevent the substantial portion of liver cancer deaths.[2, 3] Therefore, developing ultrasensitive imaging for the accurate detection of tiny malignant hepatic tumors, defined herein as tumors in a size range of $1 \sim 4 \mathrm{~mm}$ refer to the previous report,[4] is highly demanded in clinic.

During the past decades, Magnetite nanoparticles $\left(\mathrm{Fe}_{3} \mathrm{O}_{4} \mathrm{NPs}\right)$ served as $\mathrm{T}_{2}$-weighted magnetic resonance imaging (MRI) contrast agents (named as $\mathrm{T}_{2}-\mathrm{Fe}_{3} \mathrm{O}_{4}$ here), such as Feridex and Resovist were widely applied in clinic to improve the detectability of hepatic tumors. Due to the large accumulation of $\mathrm{T}_{2}-\mathrm{Fe}_{3} \mathrm{O}_{4}$ in liver parenchyma where 
contains abundant activated macrophages, hepatic tumors would be detected through pseudo-positive contrast as compared with surrounding normal liver tissue.[5, 6] However, sometimes this was lack of diagnostic sensitivity because it was difficult to differentiate solid hepatic tumors from benign lesions (e.g., hemangiomas, cysts) from the enhanced $\mathrm{T}_{2}$-weighted MR images.[3] Recently, large numbers of efforts had been devoted to optimize the parameters (e.g., sizes, morphologies or surface physiochemical properties) of $\mathrm{T}_{2}-\mathrm{Fe}_{3} \mathrm{O}_{4}$ to achieve higher transversal relaxivity $\left(\mathrm{r}_{2}\right)$ of NPs and to induce remarkable signal attenuation in normal liver tissue by using a lower dosage.[7, 8] Regardless of this, the hepatobiliary system would be still a major clearance route to degrade $\mathrm{Fe}_{3} \mathrm{O}_{4}$ NPs into iron ions, which might lead to an increased risk of toxicity.[9] So, it is desirable to construct imaging probes specifically targeting to hepatic tumors instead of liver parenchyma for the early liver cancer diagnosis. However, this progress faces many challenges. Unlike other solid tumors, nearly no specific targets exist for the detection of hepatic tumors. In addition, permeation of probes through the endothelial fenestrations to hepatic tumor cells with little capture by macrophages residing within and near the liver vasculatures is another great obstacle.[10] Consequently, probes realizing active-target imaging of hepatic tumors have been rarely reported so far.

In comparison with $\mathrm{T}_{2}-\mathrm{Fe}_{3} \mathrm{O}_{4}, \mathrm{Fe}_{3} \mathrm{O}_{4}$ served as $\mathrm{T}_{1}$-weighted MRI contrast agents (named as $\mathrm{T}_{1}-\mathrm{Fe}_{3} \mathrm{O}_{4}$ ) with precise particle engineering and rational probe decoration are ideal candidates when combined with specific ligands for hepatic tumors active targeting. It is noteworthy that $\mathrm{T}_{1}-\mathrm{Fe}_{3} \mathrm{O}_{4}$ commonly possess ultra-small particle size, which not only provides optimal bright $\mathrm{T}_{1}$ contrast effect, but also ensures that $\mathrm{T}_{1}-\mathrm{Fe}_{3} \mathrm{O}_{4}$ preferentially accumulate in tumors with little liver uptake.[9, 11-13] As a result, it could produce positive $\mathrm{T}_{1}$-weighted MRI contrast enhancement in hepatic tumor sites rather than the normal liver tissue as reported before, $[9,14,15]$ which could offer more accurate and sensitive diagnostic information during the early-stage detection of liver cancer. Unfortunately, there are many strict requirements in the process of constructing $\mathrm{T}_{1}-\mathrm{Fe}_{3} \mathrm{O}_{4}$ based active-target probes. Synthesis of $\mathrm{Fe}_{3} \mathrm{O}_{4} \mathrm{NPs}$ around core size of $5 \mathrm{~nm}$ (generally with hydrodynamic size of 10 20 nm), which has been proved to own reasonable renal excretion rate and favorable longitudinal relaxivity $\left(\mathrm{r}_{1}\right)$ is the primary request. $[4,15,16]$ Secondly, for active-target $T_{1}$ imaging of tumors, the bioconjugation reaction between specific ligands and $\mathrm{T}_{1}-\mathrm{Fe}_{3} \mathrm{O}_{4}$ must be carried out in a well-controlled manner to prevent the formation of NPs aggregates as far as possible because the aggregates usually have large magnetic moment, strong $\mathrm{T}_{2}$ effect and could be easily recognized by macrophages and accumulated in liver parenchyma. [8, 17-19] Moreover, it is incontestable that the introduction of targeting moieties will lead to an increase of serum protein adsorption and then a rapid immune clearance.[20] Because of this, dense biocompatible surface modification is additionally important to resist against the non-specific uptake by mononuclear phagocyte system (MPS; e.g., liver and spleen) in living subjects. To fulfill the request aforementioned, herein we synthesized hepatic tumors targeting probes by conjugating $\mathrm{c}$ (RGDyK) to PEGylated $\mathrm{T}_{1}-\mathrm{Fe}_{3} \mathrm{O}_{4}$. RGD peptide could efficiently target to integrin $\alpha_{v} \beta_{3}$ overexpressed endothelium cells on angiogenic tumor vessels, which are regarded as the homogeneous and common hallmarks among different kinds of solid tumors including hepatic tumors.[21, 22] Our work demonstrated that RGD-modified $\mathrm{T}_{1}-\mathrm{Fe}_{3} \mathrm{O}_{4}$ possessed optimal relaxation properties, remarkable biocompatibility and significant ability to resist against non-specific uptake. Most importantly, Excellent active-target $\mathrm{T}_{1}$ imaging results were validated on the early liver cancer models. To the best of our knowledge, this is the first report on $\mathrm{Fe}_{3} \mathrm{O}_{4}$ based contrast agents that realize active-target $\mathrm{T}_{1}$ imaging of orthotopic hepatic tumors.

\section{Materials and methods}

\section{Materials}

Iron(III) acetylacetonate (Fe(acac) $3, \quad 98 \%)$, oleylamine (80 90\%), benzyl ether (97\%) and hexane (98\%) were purchased from Aladdin Industrial Co. 1-Ethyl-(3-3-dimethylaminopropyl) carbodiimide hydrochloride (EDC-HCl), N,N'-dicyclohexylcarbodiimide (DCC), N-hydroxysuccinimide (NHS) and a, $\omega$-bis $\{2$-[(3-carboxy-1-oxopropyl)amino]ethyl\}

poly-(ethylene glycol) (carboxylated PEG, M=2000) were purchased from Sigma Aldrich. Dopamine hydrochloride was purchased from J\&K Chemical. Sodium carbonate and other organic solvents used in the syntheses were purchased from Sinopharm Chemical Reagent Co. c(RGDyK) peptide $(M=620)$ were from GLS Biochem Ltd. All the buffers and media were from Sinopharm Chemical Reagent Co. Water was purified by Millipore Water Purification System. All chemicals were used as received without further purification. All cell lines applied in this work were originally obtained from the Type Culture Collection of the Chinese Academy of Sciences (Shanghai, China) and cultured under recommended conditions. 


\section{Synthesis of hydrophobic $\mathrm{T}_{1}-\mathrm{Fe}_{3} \mathrm{O}_{4}$}

Uniform $\mathrm{T}_{1}-\mathrm{Fe}_{3} \mathrm{O}_{4}$ were synthesized via the thermal decomposition of $\mathrm{Fe}(\mathrm{acac})_{3}$ in the presence of oleylamine and benzyl ether. Specifically, $\mathrm{Fe}(\mathrm{acac})_{3}$ $(1.05 \mathrm{~g}, 3 \mathrm{mmol})$, oleylamine $(12 \mathrm{~mL}, 37 \mathrm{mmol})$ and benzyl ether $(8 \mathrm{~mL}, 42 \mathrm{mmol})$ were mixed together and placed into a $100 \mathrm{~mL}$ three-neck round-bottom flask. The mixture was stirred under a flow of $\mathrm{N}_{2}$ for $10 \mathrm{~min}$ to remove any oxygen at room temperature. Then, the mixture was heated to $220^{\circ} \mathrm{C}$ at a constant heating rate of $3.3{ }^{\circ} \mathrm{C} / \mathrm{min}$ and refluxed at this temperature for $1 \mathrm{~h}$. Next, the mixture was heated to $290{ }^{\circ} \mathrm{C}$ at the same uniform heating rate and lastly maintained at this temperature for $10 \mathrm{~min}$. As the reaction proceeded, the color of the solution changed from the initial transparent red to reddish-brown and finally opaque black. After the reaction, the mixture was rapidly cooled to room temperature. The products were separated by an external magnet, then washed three times using ethanol, and finally dissolved in $20 \mathrm{~mL}$ hexane.

\section{PEGylation of hydrophobic $\mathrm{T}_{1}-\mathrm{Fe}_{3} \mathrm{O}_{4}$}

PEG-derivatized dopamine (DA-PEG-COOH) was first synthesized. In detail, carboxylated PEG (60 $\mathrm{mg}, 0.03 \mathrm{mmol})$, NHS (6 mg, $0.05 \mathrm{mmol})$, DCC ( $9 \mathrm{mg}$, $0.04 \mathrm{mmol})$, dopamine hydrochloride $(3.9 \mathrm{mg}, 0.02$ mmol) and anhydrous $\mathrm{Na}_{2} \mathrm{CO}_{3}(30 \mathrm{mg}, 0.28 \mathrm{mmol})$ were dissolved in a mixture solvent containing $\mathrm{CHCl}_{3}$ $(6 \mathrm{~mL})$ and DMF $(3 \mathrm{~mL})$. This mixed solution was stirred $(500 \mathrm{rpm})$ for $2 \mathrm{~h}$ at $35{ }^{\circ} \mathrm{C}$ to obtain DA-PEG-COOH. Next, $15 \mathrm{mg}$ (Fe element mass in $\mathrm{Fe}_{3} \mathrm{O}_{4} \mathrm{NPs}$ ) hydrophobic $\mathrm{T}_{1}-\mathrm{Fe}_{3} \mathrm{O}_{4}$ were added and the mixed solution was continually stirred overnight (200 $\mathrm{rpm})$ at the same temperature. After the reaction, hexane was added to precipitate the PEGylated $\mathrm{T}_{1}-\mathrm{Fe}_{3} \mathrm{O}_{4}$, which were collected by an external permanent magnet and dried under $\mathrm{N}_{2}$. Lastly, PEGylated $\mathrm{T}_{1}-\mathrm{Fe}_{3} \mathrm{O}_{4}$ could be redispersed in distilled water. The extra surfactants and other salts were removed by dialysis using a dialysis bag $(\mathrm{MWCO}=8000 \sim 12000)$ in distilled water for $48 \mathrm{~h}$. Any precipitation was removed by a $220 \mathrm{~nm}$ syringe filter. The final products were stored at $4{ }^{\circ} \mathrm{C}$ for next uses.

\section{Conjugation of $c(R G D y K)$ peptide on PEGylated $\mathrm{T}_{1}-\mathrm{Fe}_{3} \mathrm{O}_{4}$}

The immobilization of $c($ RGDyK $)$ peptide $(\mathrm{M}=620)$ on PEGylated $\mathrm{T}_{1}-\mathrm{Fe}_{3} \mathrm{O}_{4}$ was according to the amide condensation reaction. EDC (35 mg, 0.183 $\mathrm{mmol}$ ), NHS (20 mg, $0.174 \mathrm{mmol}$ ) and $15 \mathrm{mg}$ (Fe element mass in $\mathrm{Fe}_{3} \mathrm{O}_{4}$ NPs) above-obtained PEGylated $\mathrm{T}_{1}-\mathrm{Fe}_{3} \mathrm{O}_{4}$ were dissolved in the MES buffer $(\mathrm{pH}=5.5)$. The mixed solution was oscillated $(120 \mathrm{rpm})$ on a shaker for $20 \mathrm{~min}$ at $20^{\circ} \mathrm{C}$. Then, the mixture was centrifuged at $4000 \mathrm{~g}$ in a ultrafiltration tube $(\mathrm{MWCO}=30000)$ to remove the extra surfactants and other salts. Subsequently, above reactants were redispersed in the $\mathrm{BB}$ buffer $(\mathrm{pH}=8.2)$ containing $\mathrm{c}$ (RGDyK) peptide $(8 \mathrm{mg}, 0.013 \mathrm{mmol})$ and then oscillated $(120 \mathrm{rpm})$ overnight at the same temperature. After the reaction, free peptide and extra salts were discarded by dialysis using the similar manner aforementioned. Any precipitation was removed by a $220 \mathrm{~nm}$ syringe filter. Finally, the purified RGD-modified $\mathrm{T}_{1}-\mathrm{Fe}_{3} \mathrm{O}_{4}$ were stored at $4{ }^{\circ} \mathrm{C}$ for long-term experiments.

\section{Characterizations}

The morphology of the nanoparticles was imaged using transmission electron microscopy (TEM) and high resolution TEM (HRTEM) (JEOL, Japan). The iron concentration of $\mathrm{Fe}_{3} \mathrm{O}_{4}$ NPs was measured with a classical C-A (absorbance versus $\mathrm{Fe}$ concentration) calibration curve on a UV-visible spectrophotometer (UV-3600, Shimadzu, Japan). Magnetism of $\mathrm{T}_{1}-\mathrm{Fe}_{3} \mathrm{O}_{4}$ was conducted on a vibrating sample magnetometer (VSM, Lakeshore 7407, USA) at room temperature. Hydrodynamic diameter $\left(\mathrm{D}_{\mathrm{H}}\right)$ and Zeta potential measurements were performed on a particle size analyzer (Malvern Zetasizer, UK). The functional groups present in the powder samples were identified using Infrared (IR) analyses on a fourier transform infrared spectrometer (FTIR, Nicolet Nexus 870, USA). The thermal behavior of the powders was studied by thermal gravimetric analyses (TGA) using a Thermo Gravimetric Analyzer (Pyris 1 DSC, USA). Iron content in different tissue samples was quantified by inductively coupled plasma atomic emission spectrometer (ICP-AES, Optima 5300DV, USA).

\section{MRI phantom studies}

To measure the $r_{1}$ and $r_{2}$ of PEGylated and RGD-modified $\mathrm{T}_{1}-\mathrm{Fe}_{3} \mathrm{O}_{4}$, all samples with different iron concentrations were obtained. $\mathrm{T}_{1^{-}}$and $\mathrm{T}_{2}$-weighted $\mathrm{MR}$ images were acquired on a clinic 3.0 T MR scanner (Verio, Siemens, Germany) with a head coil. Modified Look-Locker Inversion Recovery (MOLLI) sequence was used to measure the absolute $\mathrm{T}_{1}$ values of phantoms containing different $\mathrm{Fe}$ contents from the quantitative $\mathrm{T}_{1}$ maps. Imaging parameters were as follows: flip angle $=35, \mathrm{TR}=284.38$ $\mathrm{ms}, \mathrm{TE}=1.1 \mathrm{~ms}, \mathrm{TI}=88,188,2088,2204,4104,4221$ and $6121 \mathrm{~ms}$, field of view $(\mathrm{FOV})=340 \times 273$, matrix $=144 \times 224$, slice thickness $/$ gap $=5.0 \mathrm{~mm} / 1.0$ $\mathrm{mm}$, and $\mathrm{NEX}=8$. True Fast Image with Steady-state Precession (TrueFISP) sequence was used to measure the absolute $\mathrm{T}_{2}$ values of phantoms from the quantitative $T_{2}$ maps and the following parameters 
were adopted as flip angle $=160, T R=13200 \mathrm{~ms}, \mathrm{TE}=84$, 176 and $268 \mathrm{~ms}, \mathrm{FOV}=334 \times 334$, matrix $=320 \times 320$, slice thickness/gap $=5.0 \mathrm{~mm} / 1.0 \mathrm{~mm}$ and NEX=1.

\section{Non-specific phagocytosis and cytotoxicity experiments}

RAW 264.7 cells (Murine macrophage cells) were separately incubated with $3 \mathrm{~mL}$ culture medium containing PEGylated, RGD-modified or DMSA-modified $\mathrm{T}_{1}-\mathrm{Fe}_{3} \mathrm{O}_{4}$ for $24 \mathrm{~h}$. After removing the culture medium, the fixed cells were incubated with Prussian blue solution containing 2\% hydrochloric acid aqueous solution and $2 \%$ potassium ferrocyanide (II) trihydrate for $30 \mathrm{~min}$ to stain the intracellular $\mathrm{Fe}_{3} \mathrm{O}_{4}$ NPs. Fixed cells were counterstained with nuclear fast red, and placed under a microscope for the observation of intracellular $\mathrm{Fe}_{3} \mathrm{O}_{4} \mathrm{NPs}$ after rinse with PBS for 3 times. RAW 264.7 cells, 4T1 cells and H1975 cells were used to evaluate the cytotoxicity of the RGD-modified $\mathrm{T}_{1}-\mathrm{Fe}_{3} \mathrm{O}_{4}$. For Methyl thiazolyl tetrazolium (MTT) assay, three kinds of cells were incubated with RGD-modified $\mathrm{T}_{1}-\mathrm{Fe}_{3} \mathrm{O}_{4}$ with a series of concentrations $(0 \sim 100 \mu \mathrm{g} F / \mathrm{mL})$ for $24 \mathrm{~h}$, respectively. After this, the cells were incubated in the media with $0.5 \mathrm{mg} / \mathrm{mL}$ of MTT for $4 \mathrm{~h}$. Precipitated violet crystals were dissolved in $150 \mathrm{~mL}$ of Dimethyl sulfoxide (DMSO) and the absorbance was measured at $490 \mathrm{~nm}$ on a microplate reader. Cell viability was expressed as the percentage of viable cells compared with the control groups (cells incubated with PBS).

\section{Cellular uptake by HUVECs}

To evaluate the targeting specificity of RGD-modified $\mathrm{T}_{1}-\mathrm{Fe}_{3} \mathrm{O}_{4}$ in vitro, human umbilical vein endothelial cells (HUVECs) that overexpress integrin $\alpha_{v} \beta_{3}$ were chosen and separately incubated with $3 \mathrm{~mL}$ culture medium containing PEGylated or RGD-modified $\mathrm{T}_{1}-\mathrm{Fe}_{3} \mathrm{O}_{4}$ with a concentration of 100 $\mu \mathrm{g} \mathrm{Fe} / \mathrm{mL}$ for $12 \mathrm{~h}$. Competition experiments were conducted by adding free $\mathrm{c}(\mathrm{RGDyK})$ peptide to RGD-modified $\mathrm{T}_{1}-\mathrm{Fe}_{3} \mathrm{O}_{4}$ group in a ratio of 100:1 before NPs incubation. Culture medium was removed after incubation. The adherent cells were rinsed using PBS for 3 times. Prussian blue and nuclear fast red staining were acquired in the similar manner aforementioned before the observation of intracellular $\mathrm{Fe}_{3} \mathrm{O}_{4} \mathrm{NPs}$.

\section{In vivo MRI experiments}

Animal experiments were executed according to the protocol approved by Institutional Animal Care and Use Committee of Southeast University. Orthotopic hepatic tumor models were established by inoculation of small subcutaneous HepG2 tumor fragments into the livers of male nude mice (5-week-old, purchased from the Model Animal
Research Center of Southeast University). Specifically, $5 \times 10^{6}$ HepG2 cells in $100 \mu \mathrm{L}$ cell culture medium were subcutaneously injected into the right leg of nude mice. After implantation for 2 weeks, the subcutaneous tumor tissue was excised and cut into small cubes (size: $1 \mathrm{~mm} \times 1 \mathrm{~mm} \times 1 \mathrm{~mm}$ ). Next, the tumor cubes were transplanted into the livers (the upper lobes) of nude mice by using microsurgical operation. 2-week inoculation later, the mice bearing orthotopic hepatic tumor in a size range of $2 \sim 3 \mathrm{~mm}$ were subjected into 2 groups (one active targeting group and one non-active targeting group, 3 tumor-bearing mice per group) for the following MRI studies. After intravenous injection of RGD-modified $\mathrm{T}_{1}-\mathrm{Fe}_{3} \mathrm{O}_{4}$ or PEGylated $\mathrm{T}_{1}-\mathrm{Fe}_{3} \mathrm{O}_{4}$ with a dose of $5.0 \mathrm{mg}$ $\mathrm{Fe} / \mathrm{kg}, \mathrm{T}_{1}$-weighted MR images across the tumor in transverse plane were acquired by using Multi Slice Multi Echo (MSME) sequence (Respiratory gating contained) on a 7.0 T Micro-MR scanner (PharmaScan, Brukers, Germany) with the following parameters: flip angle $=180, \mathrm{TR}=498.3 \mathrm{~ms}, \mathrm{TE}=14.0 \mathrm{~ms}, \mathrm{FOV}=3 \times 3$, matrix $=256 \times 256, S I=1.0 \mathrm{~mm} / 1.0 \mathrm{~mm}$, averages $=3$, slices $=16, \mathrm{NEX}=1$. Subsequently, $\mathrm{T}_{2}$-weighted images were acquired by using Rapid Acquisition Relaxation Enhanced (RARE) sequence (Respiratory gating contained) under the following parameters: flip angle $=180, \mathrm{TR}=2500.0 \mathrm{~ms}, \mathrm{TE}=33.0 \mathrm{~ms}, \mathrm{FOV}=3 \times 3$, matrix $=256 \times 256$, SI $=1.0 \mathrm{~mm} / 1.0 \mathrm{~mm}$, averages $=3$, slices $=16, N E X=1$. MR images were obtained before and at differential time points of 10,20,30, 60, 120 and $180 \mathrm{~min}$ post administration. Signal-to-noise ratio (SNR) was calculated for each mouse to qualify the signal enhancement in the region of interest (ROI) by the following equation: $\mathrm{SNR}=\mathrm{SI} / \mathrm{SD}_{\text {noise, }}$ where SI stands for signal intensity in ROIs and SD stands for standard deviation analyzed from the MR images. The values of $S N R_{\text {post }} / \mathrm{SNR}_{\text {pre }}$ were calculated to represent the signal changes. Tumor-to-liver contrast-to-noise ratio (CNR) here was introduced for each mouse to qualify the efficacy of contrast enhancement in hepatic tumors comparing with the surrounding normal liver tissue, where $\mathrm{CNR}=\left(\mathrm{SNR}_{\text {tumor }}-\mathrm{SNR}_{\text {liver }}\right) / \mathrm{SNR}_{\text {tumor. }}$. The values of $\mathrm{CNR}_{\text {post }} / \mathrm{CNR}_{\text {pre }}$ were calculated to represent the signal changes.

\section{Histopathological staining}

Tumors and livers from 6 experimental mice $(3$ injected with RGD-modified $\mathrm{T}_{1}-\mathrm{Fe}_{3} \mathrm{O}_{4}$ and 3 injected with PEGylated $\mathrm{T}_{1}-\mathrm{Fe}_{3} \mathrm{O}_{4}$ ) were excised and fixed in $10 \%$ neutral buffered formalin for 2 days. Then, the tissues were processed routinely into paraffin and sectioned into 5-micrometer thickness slices. For Prussian blue staining, the sections were put into Prussian blue solution and incubated at room 
temperature for $30 \mathrm{~min}$. After rinse with PBS, sections were counterstained with nuclear fast red. After rinsing again, sections were dehydrated by $70 \%, 80 \%$ and $100 \%$ ethanol, then transferred into xylene, and finally mounted. Sections could be observed under an optical microscopy. An immunohistochemical analysis method was used to further evaluate the specific location of RGD-modified $\mathrm{T}_{1}-\mathrm{Fe}_{3} \mathrm{O}_{4}$ accumulated in hepatic tumors. Tumor angiogenesis were firstly stained with primary rat anti-mouse CD31 antibody. CD31 staining with brown color could be reached by using glucose oxidase-diaminobenzidine (DAB) method. The procedures for Prussian blue and nuclear fast red staining were virtually the same aforementioned and then the sections could be observed under an optical microscopy.

\section{In vivo blood half-life and biodistribution studies}

5-week-old mice were adopted for the blood half-life studies of RGD-modified $\mathrm{T}_{1}-\mathrm{Fe}_{3} \mathrm{O}_{4}$, which was intravenously injected into the mice $(n=6)$. The dose level was the same as that for imaging experiments. Blood samples were obtained via retro-orbital blood collection at $0 \mathrm{~min}, 5 \mathrm{~min}, 15 \mathrm{~min}, 30 \mathrm{~min}, 1 \mathrm{~h}, 2 \mathrm{~h}, 4 \mathrm{~h}$, $8 \mathrm{~h}$ postinjection. Then, the samples were digested by aqua regia solution (nitric acid/hydrochloric acid, volume/volume $=1: 3$ ) after the red blood cells were removed by centrifugation at $1000 \mathrm{rpm}$. The Fe content in different samples was determined by ICP-AES. Tumor-bearing mice were euthanized at $5 \mathrm{~h}$ post-injection ( 3 injected with $\mathrm{RGD}$-modified $\mathrm{T}_{1}-\mathrm{Fe}_{3} \mathrm{O}_{4}$ and 3 injected with PEGylated $\mathrm{T}_{1}-\mathrm{Fe}_{3} \mathrm{O}_{4}$, the dose level was the same as that for imaging experiments). The heart, liver, spleen, lung, kidney and tumor were extracted and weighed. The tissues were then cut into pieces and digested by aqua regia solution for $24 \mathrm{~h}$. The Fe content in different tissues was quantified by ICP-AES. For comparison, 3 mice without injection were used as control group.

\section{Statistical analysis}

Student's $t$ test statistical analysis was performed to evaluate the significance of the experimental data. A $p$ value of 0.05 was selected as the level of significance. The data was indicated with $\left(^{*}\right)$ for $p<0.05$ and $\left(^{* *}\right)$ for $p<0.01$, respectively.

\section{Results and Discussion}

\section{Preparation and characterizations of RGD-modified $\mathrm{T}_{1}-\mathrm{Fe}_{3} \mathrm{O}_{4}$}

Uniform $\mathrm{T}_{1}-\mathrm{Fe}_{3} \mathrm{O}_{4}$ was synthesized via thermal decomposition of $\mathrm{Fe}(\mathrm{acac})_{3}$ as precursors in the presence of oleylamine and benzyl ether. TEM image presented that oleylamine coated $\mathrm{T}_{1}-\mathrm{Fe}_{3} \mathrm{O}_{4}$ had a relatively narrow size distribution with mean core size of $5.3 \pm 0.6 \mathrm{~nm}$ (Figure S1). The hydrophobic NPs could be easily transformed to aqueous medium for further applications through a simple and effective ligand exchange reaction with the biocompatible ligands, carboxylated PEG (Figure 1a). As mentioned in Materials and methods section, PEG ligands bearing a dopamine group at one end (denoted as DA-PEG-COOH) were firstly fabricated, and the catechol units of dopamine having strong binding affinity to transition metal were chosen as anchor groups to decorate on the surface of $\mathrm{T}_{1}-\mathrm{Fe}_{3} \mathrm{O}_{4}$ by replacing the oleylamine molecular. According to the TEM and HRTEM images (Figure 2a and b), PEGylated $\mathrm{T}_{1}-\mathrm{Fe}_{3} \mathrm{O}_{4}$ were monodispersed in quasi-spherical shapes with good crystalline and negligible surface etching. Dynamic light scattering (DLS) measurements revealed that PEGylated $\mathrm{T}_{1}-\mathrm{Fe}_{3} \mathrm{O}_{4}$ had ultra-small $\mathrm{D}_{\mathrm{H}}$ of $10 \pm 0.7 \mathrm{~nm}$ and homogeneously dispersed in aqueous media without detectable aggregation (Figure 2d). Meanwhile, free carboxylic groups existing on DA-PEG-COOH made it possible to construct tumor targeting probes via conjugating specific ligands. In our work, a kind of small molecular weight peptide, $\mathrm{c}(\mathrm{RGDyK})$, was chosen to covalently conjugate on $\mathrm{T}_{1}-\mathrm{Fe}_{3} \mathrm{O}_{4}$ surface through the formation of amide bonds (Figure 1b). This cyclized RGD peptide has been proven to specifically target to integrin $\alpha_{v} \beta_{3}$, which is overexpressed on tumor angiogenesis.[23-25]

The formation of RGD-modified $\mathrm{T}_{1}-\mathrm{Fe}_{3} \mathrm{O}_{4}$ was investigated by a series of characterizations in careful comparisons with the corresponding PEGylated $\mathrm{T}_{1}-\mathrm{Fe}_{3} \mathrm{O}_{4}$. Figure $2 \mathrm{c}$ is representative TEM image of RGD-modified $\mathrm{T}_{1}-\mathrm{Fe}_{3} \mathrm{O}_{4}$. Nearly no differences were detected in their core morphology and RGD-modified $\mathrm{T}_{1}-\mathrm{Fe}_{3} \mathrm{O}_{4}$ was distributed with an increasing distance between the particles. These tendencies could be supported by the following DLS measurements (Figure $2 \mathrm{~d}$ ). $\mathrm{D}_{\mathrm{H}}$ of RGD-modified $\mathrm{T}_{1}-\mathrm{Fe}_{3} \mathrm{O}_{4}$ slightly increased from $10 \mathrm{~nm}$ to $15 \mathrm{~nm}$ right after the conjugation reaction. It also could be demonstrated that the conjugation reaction was well-controlled from the magnetic properties of PEGylated and RGD-modified $\mathrm{T}_{1}-\mathrm{Fe}_{3} \mathrm{O}_{4}$, which are strongly dependent on the sizes and status (dispersed or aggragated) of $\mathrm{Fe}_{3} \mathrm{O}_{4}$ NPs. Field-dependent magnetic hysteresis loops showed that both PEGylated and RGD-modified $\mathrm{T}_{1}-\mathrm{Fe}_{3} \mathrm{O}_{4}$ exhibited favorable superparamagnetic behavior with roughly equal saturated magnetic moment ( $\sim 50 \mathrm{emu} / \mathrm{g}$ Fe element mass in $\mathrm{Fe}_{3} \mathrm{O}_{4} \mathrm{NPs}$, Figure 2e), indicating that no unexpected aggregation or clusters further formed during the conjugation reaction. IR analyses were 
investigated to qualitatively confirm the presence of $\mathrm{c}(\mathrm{RGDyK})$ peptide on $\mathrm{T}_{1}-\mathrm{Fe}_{3} \mathrm{O}_{4}$. From IR spectra (Figure S2), the peak at $1100 \mathrm{~cm}^{-1}$ was attributed to the stretching vibration of C-O-C group from PEG ligand. A strong peak occurred at $1600 \mathrm{~cm}^{-1}$ for RGD-modified $\mathrm{T}_{1}-\mathrm{Fe}_{3} \mathrm{O}_{4}$, which was caused by the vibration of $-\mathrm{NH}_{2}$ group and in consistent with the free RGD peptide, demonstrating the successful conjugation. Zeta potentials of PEGylated and RGD-modified $\mathrm{T}_{1}-\mathrm{Fe}_{3} \mathrm{O}_{4}$ in neutral aqueous were $-41 \pm 3 \mathrm{mV}$ and $-11 \pm 2 \mathrm{mV}$, respectively (Figure S3a and b). The reduction in negative charge after conjugation was due to the partial absence of free carboxylic groups on RGD-modified $\mathrm{T}_{1}-\mathrm{Fe}_{3} \mathrm{O}_{4}$. TGA were performed to estimate the efficiency of the conjugation. It presented that the relative loss weight of PEGylated $\mathrm{T}_{1}-\mathrm{Fe}_{3} \mathrm{O}_{4}$ was about $54.26 \%$, while this value increased to $57.92 \%$ for RGD-modified $\mathrm{T}_{1}-\mathrm{Fe}_{3} \mathrm{O}_{4}$ (Figure S4). According to the method reported previously,[12] the number of PEG and c(RGDyK) conjugated on the surface of one $\mathrm{Fe}_{3} \mathrm{O}_{4} \mathrm{NP}$ could be roughly estimated as high as 117.8 and 78.5 respectively, and the conjugation efficiency was about $66.7 \%$ (the molar ratio between free carboxylic groups existed on PEGylated $\mathrm{T}_{1}-\mathrm{Fe}_{3} \mathrm{O}_{4}$ and the $\mathrm{c}$ (RGDyK) peptide successfully conjugated). In addition, RGD-modified $\mathrm{T}_{1}-\mathrm{Fe}_{3} \mathrm{O}_{4}$ exhibited excellent stability in aqueous dispersion during a long period time of 15 months without obvious aggregation (Figure S5), which was benefit from the denser PEG coating on
$\mathrm{T}_{1}-\mathrm{Fe}_{3} \mathrm{O}_{4}$ in comparison with other PEGylated NPs reported previously.[12, 26, 27]

\section{Relaxivity measurements}

Relaxivity measurements were performed at the clinically relevant magnetic field strength of $3.0 \mathrm{~T}$, which could better reflect the relaxation properties of NPs for clinic application. Figure 3a showed the $\mathrm{T}_{1}$-weighted images of PEGylated and RGD-modified $\mathrm{T}_{1}-\mathrm{Fe}_{3} \mathrm{O}_{4}$ at different $\mathrm{Fe}$ concentrations in distilled water or $20 \%$ fetal bovine serum (FBS) solution. Herein, NPs were incubated with FBS before MR studies in order to investigate their relaxation properties sustaining from the adsorption of serum proteins under physiological conditions. Evidently, no matter in water or FBS solution, all test samples induced favorable bright contrast enhancement even at an extremely low Fe concentration of $0.09 \mathrm{mM}$. To further evaluate their $\mathrm{T}_{1}$ contrast efficacy, $\mathrm{r}_{1}$ and $\mathrm{r}_{2}$ of PEGylated and RGD-modified $\mathrm{T}_{1}-\mathrm{Fe}_{3} \mathrm{O}_{4}$ in different medium were extracted (Figure $3 b$ and $c$ ). PEGylated and RGD-modified $\mathrm{T}_{1}-\mathrm{Fe}_{3} \mathrm{O}_{4}$ exhibited relatively high $\mathrm{r}_{1}$ of $7.82 \pm 0.28 \mathrm{mM}^{-1} \mathrm{~s}^{-1}$ and $7.74 \pm 0.22 \mathrm{mM}^{-1} \mathrm{~s}^{-1}$ in distilled water, respectively. After incubation with FBS for $4 \mathrm{~h}, \mathrm{r}_{1}$ of both samples slightly decreased whereas $r_{2}$ had some increase and hence the $r_{2} / r_{1}$ ratio raised (Figure $3 \mathrm{~d}$ ). This phenomenon was probably due to the occurrence of the irreversible, partial aggregation of NPs during the incubation which was known to be responsible for the shortening of

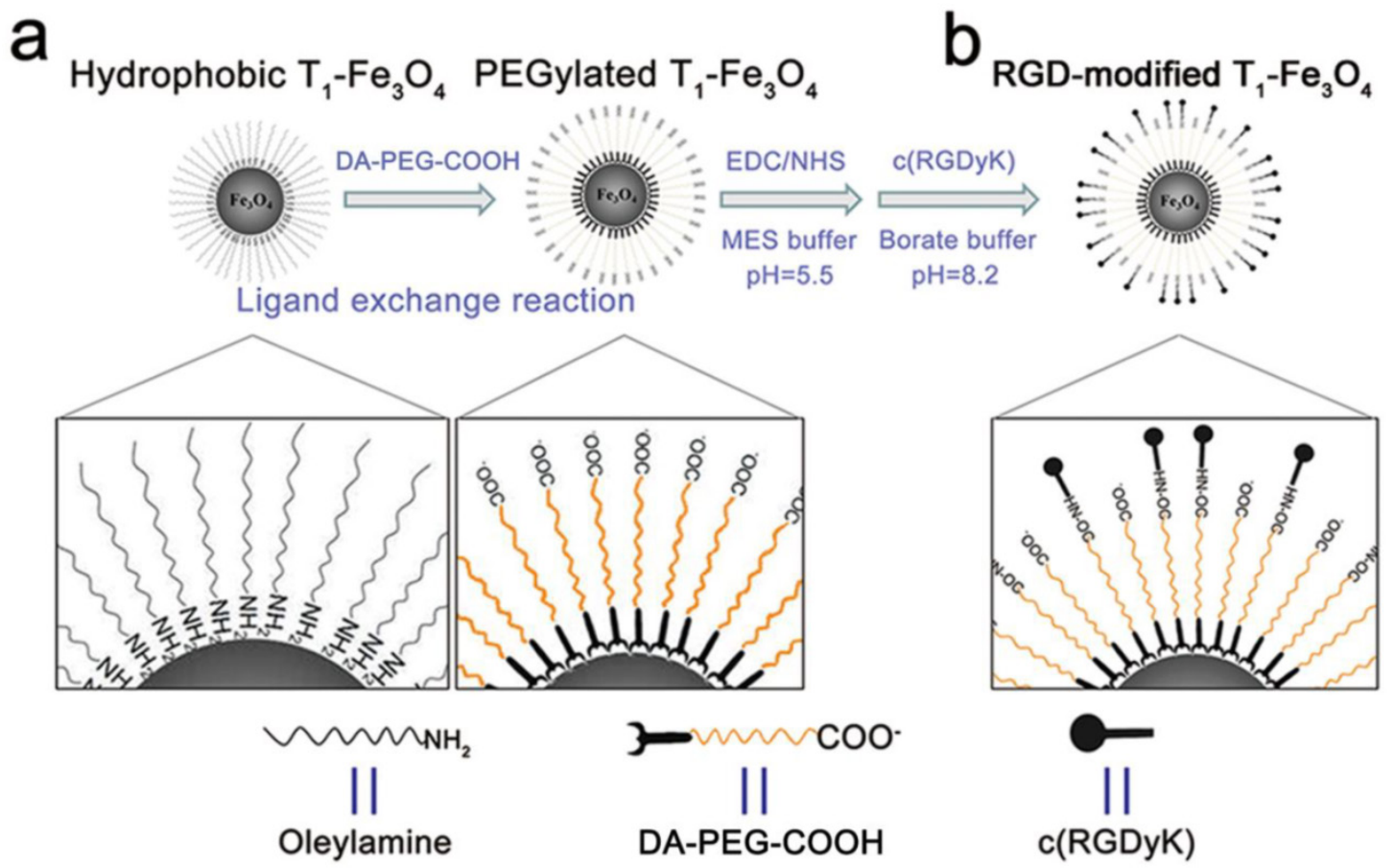

Figure 1. Schematic illustration of PEGylated $\mathrm{T}_{1}-\mathrm{Fe}_{3} \mathrm{O}_{4}$ and RGD-modified $\mathrm{T}_{1}-\mathrm{Fe}_{3} \mathrm{O}_{4}$ syntheses. (a) Hydrophobic $\mathrm{T}_{1}-\mathrm{Fe}_{3} \mathrm{O}_{4}$ were transformed to water-dispersible through a ligand exchange reaction with DA-PEG-COOH. (b) c(RGDyK) peptide was conjugated through the formation of amide bonds via free carboxyl groups on the surface of PEGylated $\mathrm{T}_{1}-\mathrm{Fe}_{3} \mathrm{O}_{4}$. 
transversal relaxation time. In this case, RGD-modified $\mathrm{T}_{1}-\mathrm{Fe}_{3} \mathrm{O}_{4}$ with larger $\mathrm{D}_{\mathrm{H}}$ would have stronger steric hindrance effect against the aggregation processes that would affect its relaxation properties. Nevertheless, PEGylated and RGD-modified $\mathrm{T}_{1}-\mathrm{Fe}_{3} \mathrm{O}_{4}$ still held relatively low $\mathrm{r}_{2} / \mathrm{r}_{1}$ ratio comparing with other $\mathrm{Fe}_{3} \mathrm{O}_{4}$ based $\mathrm{T}_{1}$ contrast agents reported previously.[9, 11-14, 28] Generally, low $r_{2} / r_{1}$ ratio is a key parameter widely used to confirm the strong $\mathrm{T}_{1}$ contrast efficiency of one MRI contrast agent.[28] The relaxivities of these two NPs in distilled water were also measured on a $7.0 \mathrm{~T}$ Micro-MR scanner and the results were shown in Figure S6, respectively. At $7.0 \mathrm{~T}$, the $\mathrm{r}_{2}$ value was much higher since the transversal relaxation time of $\mathrm{Fe}_{3} \mathrm{O}_{4}$ NPs was highly field strength dependent. However, these values were still comparable with some previous reports measured under the same condition.[9] More importantly, optimal $\mathrm{T}_{1}$ relaxation property of RGD-modified $\mathrm{T}_{1}-\mathrm{Fe}_{3} \mathrm{O}_{4}$ could kept as long as 15 months (Figure S7), which was in good agreement with its colloidal stability investigated before, and was highly essential for RGD-modified $\mathrm{T}_{1}-\mathrm{Fe}_{3} \mathrm{O}_{4}$ when used as long-term stable $\mathrm{T}_{1}$ contrast agent for further applications.

\section{In vitro studies}

Another key consideration for the in vivo use of NPs for tumor targeting is assessing their ability to resist against the non-specific uptake by MPS in living subjects. NPs without suitable surface modification would significantly increase the non-specific recognition by macrophages and facilitate the elimination of NPs.[29-31] Herein, we conducted cellular phagocytosis experiments of PEGylated and RGD-modified $\mathrm{T}_{1}-\mathrm{Fe}_{3} \mathrm{O}_{4}$ by using RAW 264.7 cells belonging to murine macrophages as preludes to the in vivo studies. Meanwhile, another common ligand modified $\mathrm{T}_{1}-\mathrm{Fe}_{3} \mathrm{O}_{4}$, known as meso-2, 3-dimercaptosuccinic acid (DMSA)-modified $\mathrm{T}_{1}-\mathrm{Fe}_{3} \mathrm{O}_{4}$ were tested under the same condition as a comparison.[32] Representative microscopy images of RAW 264.7 cells after incubation with $\mathrm{T}_{1}-\mathrm{Fe}_{3} \mathrm{O}_{4}$ and Prussian blue staining were shown in Figure 4a-c. It could be observed that PEGylated and RGD-modified $\mathrm{T}_{1}-\mathrm{Fe}_{3} \mathrm{O}_{4}$ incubation induced non-detectable cellular uptake whereas nearly all RAW 264.7 cells incubated with DMSA-modified $\mathrm{T}_{1}-\mathrm{Fe}_{3} \mathrm{O}_{4}$ were stained with blue even at an extremely low concentration of $12.5 \mu \mathrm{g}$ $\mathrm{Fe} / \mathrm{mL}$ (Figure S8). These results confirmed the significant effect of PEGylation to drastically minimize the non-specific phagocytosis by macrophages even

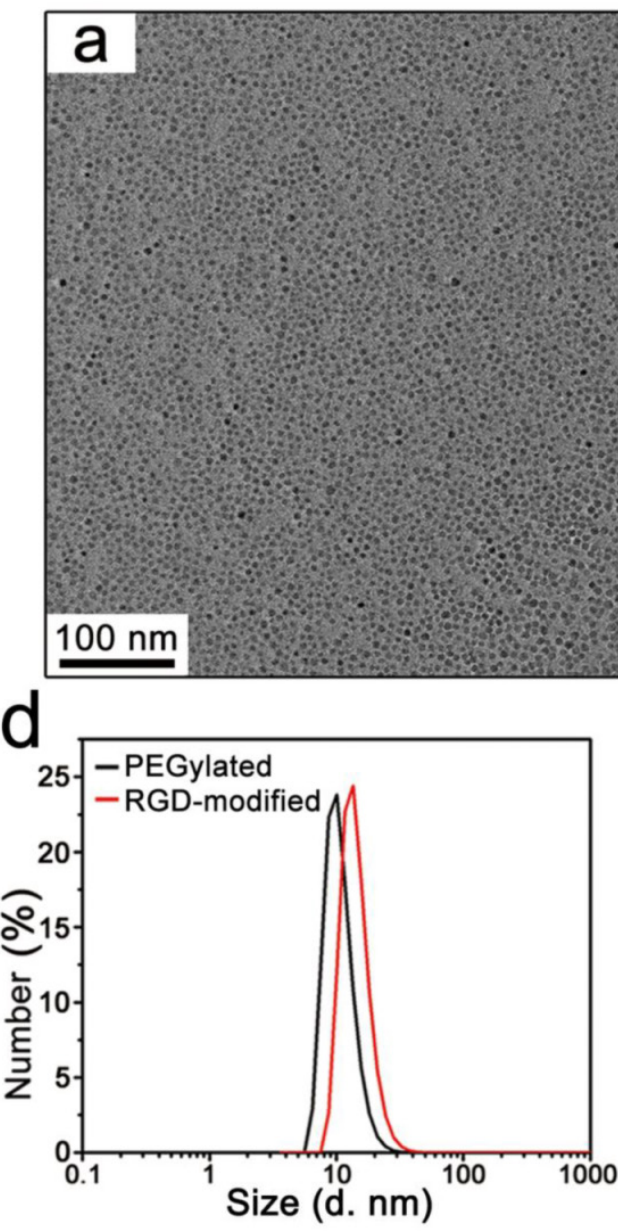

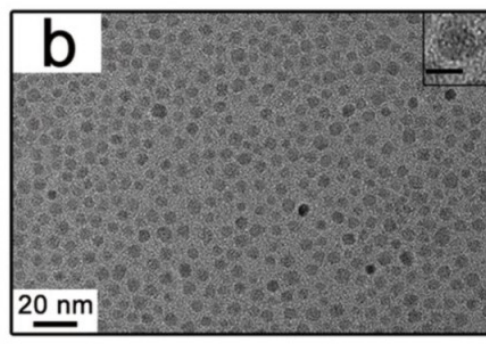
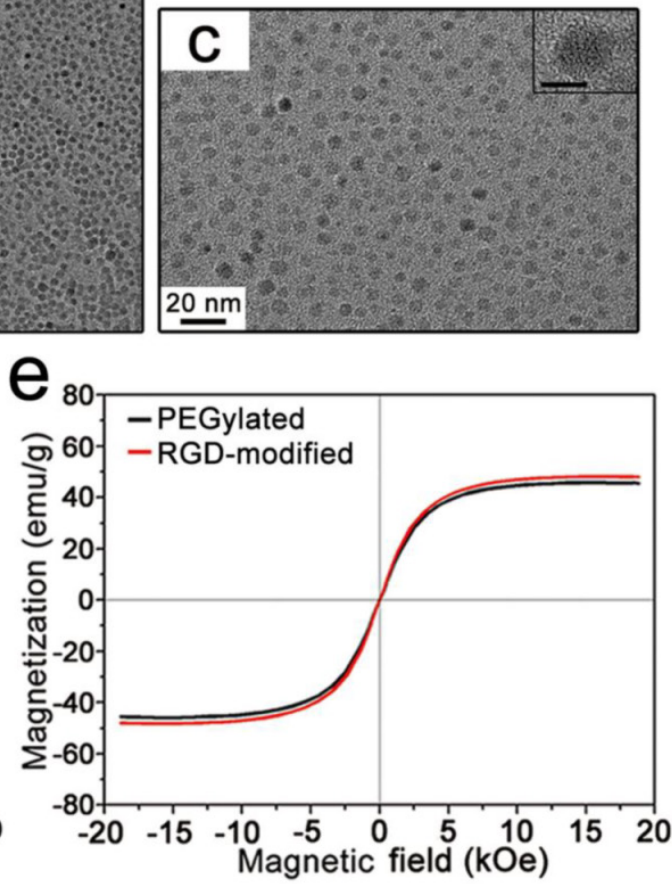
though there were large numbers of $c$ (RGDyK) peptide on PEGylated NPs surface, which would endow RGD-modified $\mathrm{T}_{1}-\mathrm{Fe}_{3} \mathrm{O}_{4}$ with prolonged blood half-life to reach tumors in vivo.

Figure 2. (a) TEM image of monodispersed PEGylated $\mathrm{T}_{1}-\mathrm{Fe}_{3} \mathrm{O}_{4}$. (b) The higher magnification TEM image of PEGylated $\mathrm{T}_{1}-\mathrm{Fe}_{3} \mathrm{O}_{4}$. (inset: HRTEM image. Scale bar, $5 \mathrm{~nm}$ ) (c) TEM image of monodispersed RGD-modified $\mathrm{T}_{1}-\mathrm{Fe}_{3} \mathrm{O}_{4}$. (inset: HRTEM image. Scale bar, $5 \mathrm{~nm}$ ). (d) $\mathrm{D}_{\mathrm{H}}$ of PEGylated $\mathrm{T}_{1}-\mathrm{Fe}_{3} \mathrm{O}_{4}$ and RGD-modified $\mathrm{T}_{1}-\mathrm{Fe}_{3} \mathrm{O}_{4}$. The sizes were measured from water solution by DLS. (e) Field-dependent magnetic hysteresis loops of PEGylated $\mathrm{T}_{1}-\mathrm{Fe}_{3} \mathrm{O}_{4}$ and RGD-modified $\mathrm{T}_{1}-\mathrm{Fe}_{3} \mathrm{O}_{4}$ recorded at room temperature. 


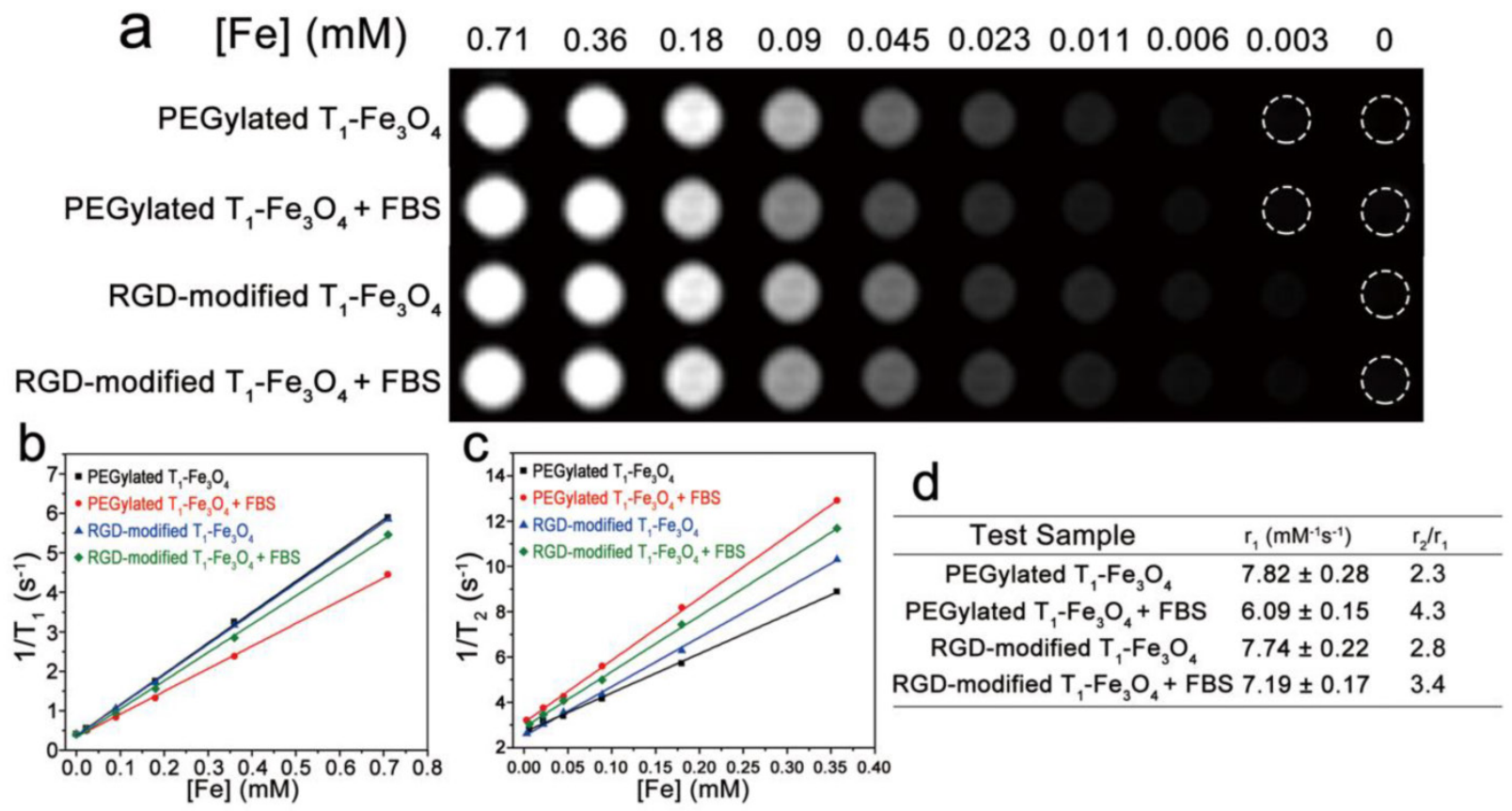

Figure 3. (a) $\mathrm{T}_{1}$-weighted MR images of $\mathrm{PEGylated} \mathrm{T}_{1}-\mathrm{Fe}_{3} \mathrm{O}_{4}$ and $\mathrm{RGD}$-modified $\mathrm{T}_{1}-\mathrm{Fe}_{3} \mathrm{O}_{4}$ at different $\mathrm{Fe}$ concentrations in water or $20 \% \mathrm{FBS}$ solutions. Plots of (b) $1 / \mathrm{T}_{1}$ and (c) $1 / \mathrm{T}_{2}$ against Fe concentration of PEGylated $\mathrm{T}_{1}-\mathrm{Fe}_{3} \mathrm{O}_{4}$ and $\mathrm{RGD}$-modified $\mathrm{T}_{1}-\mathrm{Fe}_{3} \mathrm{O}_{4}$ in water or $20 \% \mathrm{FBS}$ solutions at $3.0 \mathrm{~T}$. $\mathrm{r}_{1}$ and $\mathrm{r}_{2}$ were calculated from the slopes of the corresponding linear fits of the experimental data. (d) Relaxation properties of different test samples measured in (b) and (c).
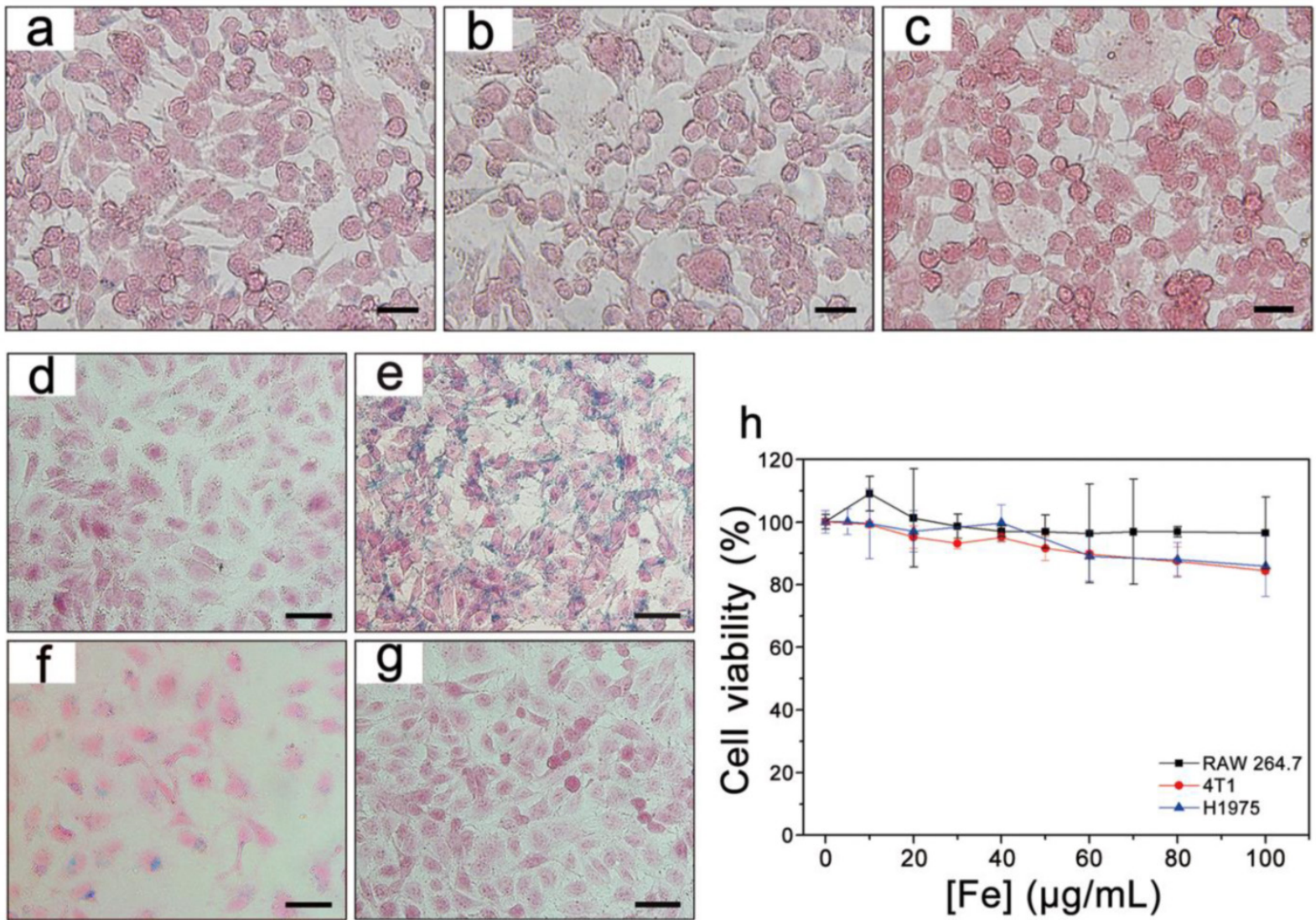

Figure 4. Prussian blue staining of RAW 264.7 macrophages incubated with (a) PEGylated $\mathrm{T}_{1}-\mathrm{Fe}_{3} \mathrm{O}_{4}$, (b) RGD-modified $\mathrm{T}_{1}-\mathrm{Fe}_{3} \mathrm{O}_{4}$ and (c) control group for $24 \mathrm{~h}$ at $\mathrm{Fe}$ concentration of $100 \mu \mathrm{g} / \mathrm{mL}$. Prussian blue staining of HUVECs incubated with (d) PEGylated $\mathrm{T}_{1}-\mathrm{Fe}_{3} \mathrm{O}_{4}$, (e) RGD-modified $\mathrm{T}_{1}-\mathrm{Fe}_{3} \mathrm{O}_{4}$, (f) $\mathrm{RGD}$-modified $\mathrm{T}_{1}$-Fe $\mathrm{Fe}_{3} \mathrm{O}_{4}$ plus free c(RGDyK) peptide (competition group) and (g) control group for $12 \mathrm{~h}$ at Fe concentration of $100 \mu \mathrm{g} / \mathrm{mL}$. (h) Cytotoxic effects of RGD-modified $\mathrm{T}_{1}$-Fe $\mathrm{F}_{3} \mathrm{O}_{4}$ on RAW 264.7, 4Tl and $\mathrm{H} 1975$ cells measured with the MTT assay kit by incubation with various concentrations of Fe for $24 \mathrm{~h}$. The error bars represented $\pm s . d$. of six independent experiments. Scale bar: $20 \mu \mathrm{m}$ for all images. 
In order to evaluate the targeting specificity to integrin $\alpha_{v} \beta_{3}$, RGD-modified $\mathrm{T}_{1}-\mathrm{Fe}_{3} \mathrm{O}_{4}$ were incubated with HUVECs (a kind of cells overexpress integrin $\left.\mathrm{a}_{\mathrm{v}} \beta_{3}\right)$ and PEGylated $\mathrm{T}_{1}-\mathrm{Fe}_{3} \mathrm{O}_{4}$ were incubated under the same condition as the negative control.[33] Besides, the competition experiments were conducted by adding free $\mathrm{c}(\mathrm{RGDyK})$ to RGD-modified $\mathrm{T}_{1}-\mathrm{Fe}_{3} \mathrm{O}_{4}$ group in a ratio of 100:1 to block the integrin region. Figure $4 \mathrm{~d}-\mathrm{g}$ presented the Prussian blue staining of HUVECs after incubation. Strong targeting specificity was observed for RGD-modified $\mathrm{T}_{1}-\mathrm{Fe}_{3} \mathrm{O}_{4}$ group whereas there was no detectable NPs for PEGylated $\mathrm{T}_{1}-\mathrm{Fe}_{3} \mathrm{O}_{4}$ group. Blocking the integrin $\mathrm{a}_{\mathrm{v}} \beta_{3}$ with free $c($ RGDyK) led to significant decrease of blue deposition, providing a direct evidence that RGD-modified $\mathrm{T}_{1}-\mathrm{Fe}_{3} \mathrm{O}_{4}$ specifically targeted to HUVECs via the interaction between RGD on $\mathrm{T}_{1}-\mathrm{Fe}_{3} \mathrm{O}_{4}$ and the integrin $\alpha_{v} \beta_{3}$ expressing on HUVECs. Moreover, the prominent target specificity still maintained after 15 months (Figure S9). This was benefit from the higher stability of $\mathrm{c}(\mathrm{RGDyK})$ comparing with other tumor-specific ligands (e.g., antibodies) which are easier to loss bioactivities. Notably, this was quite long time reported so far for imaging probes to keep their targeting specificity.

MTT assays were carried out to evaluate the cytotoxicity of RGD-modified $\mathrm{T}_{1}-\mathrm{Fe}_{3} \mathrm{O}_{4}$ in vitro. Figure 4 h presented that cell viability exceeded $80 \%$ even at a high incubating concentration of $100 \mu \mathrm{g} \mathrm{Fe} / \mathrm{mL}$, which was much higher than the clinical dose for Feridex (0.56 mg Fe/kg body weight), demonstrating the low cytotoxicity and favorable biocompatibility of RGD-modified $\mathrm{T}_{1}-\mathrm{Fe}_{3} \mathrm{O}_{4}$ as MRI contrast agent for in vivo applications.

\section{Active-target $T_{1}$ imaging of hepatic tumors in vivo}

With the properties of low non-specific macrophages uptake and high targeting specificity to integrin $\alpha_{v} \beta_{3}$, we further verified the active-target $T_{1}$ imaging ability of RGD-modified $\mathrm{T}_{1}-\mathrm{Fe}_{3} \mathrm{O}_{4}$ on orthotopic hepatic tumors in vivo. Notably, orthotopic tumor models conducted here not only reflected the natural environment of hepatic tumors, but also could be taken as metastases in liver.[34] After intravenous injection of RGD-modified $\mathrm{T}_{1}-\mathrm{Fe}_{3} \mathrm{O}_{4}$ at a dose of $5 \mathrm{mg}$ $\mathrm{Fe} / \mathrm{kg}$ (calculated in terms of Fe element mass per kilogram of mice body weight), we indeed observed the bright contrast enhancement in tumor over time, leading to easy identification of the tumor as small as $2.2 \mathrm{~mm}$ from surrounding normal liver tissue (Figure 5a). According to the formula in Materials and methods section, tumor-to-liver CNR was calculated to quantify signal changes and it increased rapidly to reach the maximum at 30 min which was about 3.33 times stronger than pre-injection (Figure 5b). To further demonstrate the active targeting of RGD-modified $\mathrm{T}_{1}-\mathrm{Fe}_{3} \mathrm{O}_{4}$, the corresponding PEGylated $\mathrm{T}_{1}-\mathrm{Fe}_{3} \mathrm{O}_{4}$ were injected at a same dose for comparison to conduct the non-active-target imaging (Figure S10). Obviously, the latter induced weaker bright contrast and it took longer to reach the maximum tumor-to-liver CNR, which can be interpreted by the limited tumor uptake of PEGylated $\mathrm{T}_{1}-\mathrm{Fe}_{3} \mathrm{O}_{4}$ through the enhanced permeation and retention (EPR) effect.[4] At the same time, we also examined the liver uptake of NPs by calculating liver SNR changes from $T_{1}$ and $T_{2}$ images because the signal in liver would obviously drop in $\mathrm{T}_{2}$ images if $\mathrm{Fe}_{3} \mathrm{O}_{4}$ NPs largely accumulated in liver parenchyma (Figure S11). While, SNR value in normal liver tissue, no matter in $\mathrm{T}_{1}$-weighted images or $\mathrm{T}_{2}$-weighted images, was almost unchanged after the injection of both NPs, indicating their little liver uptake (Figure S12). After imaging test, hepatic tumors and normal liver tissue from the experimental mice (injected with RGD-modified or PEGylated $\mathrm{T}_{1}-\mathrm{Fe}_{3} \mathrm{O}_{4}$ ) were harvested and stained with Prussian blue. Obvious blue spots appeared in tumor while they were hardly found in normal liver tissue for the active targeting group (Figure $6 \mathrm{a}, \mathrm{b}$ and $\mathrm{d}$ ), suggesting that RGD-modified $\mathrm{T}_{1}-\mathrm{Fe}_{3} \mathrm{O}_{4}$ specifically targeted to hepatic tumor with little undesired phagocytosis in liver parenchyma. Although PEGylated $\mathrm{T}_{1}-\mathrm{Fe}_{3} \mathrm{O}_{4}$ exhibited the similar liver phagocytosis result (Figure S13a), it was difficult for non-active targeting NPs to permeate into hepatic tumors due to the limited EPR effect (Figure S13b). The present RGD-modified and PEGylated $\mathrm{T}_{1}-\mathrm{Fe}_{3} \mathrm{O}_{4}$ were more resistant to non-specific uptake than the NPs reported in other studies, which still mainly accumulated in liver parenchyma,[27] can be ascribed to its ultra-small hydrodynamic size, denser PEG coating and higher stability in aqueous dispersion as revealed in our former experiments. The immunohistochemical staining of CD31 definitely disclosed that the RGD-modified $\mathrm{T}_{1}-\mathrm{Fe}_{3} \mathrm{O}_{4}$ accumulated in tumor were mostly localized on the integrin $\alpha_{v} \beta_{3}$ expressing tumor angiogenesis (brown color stained), which were the preferential and specific targets of RGD-modified $\mathrm{T}_{1}-\mathrm{Fe}_{3} \mathrm{O}_{4}$ for hepatic tumors active targeting in vivo (Figure 6c).

Accordingly, differ from the traditional liver tumor imaging through pseudo-positive contrast effects by using $\mathrm{T}_{2}-\mathrm{Fe}_{3} \mathrm{O}_{4}$ that induce dark signal in normal liver tissue (Figure 5c), RGD-modified $\mathrm{T}_{1}-\mathrm{Fe}_{3} \mathrm{O}_{4}$ having ultra-small $\mathrm{D}_{\mathrm{H}}$ and appropriate surface decoration could specifically target to tumor angiogenesis to produce bright contrast enhancement in hepatic tumors with little liver phagocytosis 
(Figure 5d). This novel active-target $\mathrm{T}_{1}$-weighted imaging could significantly improve the sensitivity of early liver cancer detection and effectively minimize the potential toxicity of heavy metals in body at the same time, which is of great importance in clinical diagnosis.

\section{In vivo biodistribution}

Blood half-life and biodistribution of RGD-modified $\mathrm{T}_{1}-\mathrm{Fe}_{3} \mathrm{O}_{4}$ were quantitatively analyzed to further disclose its pharmacokinetic behavior in vivo (Figure 7). By fitting the blood concentrations of RGD-modified $\mathrm{T}_{1}-\mathrm{Fe}_{3} \mathrm{O}_{4}$ acquired at different time points postinjection, the blood half-life was estimated to be $92 \mathrm{~min}$, which was much longer than that of clinical Gd complex small molecules (several minutes in small animals) and other iron oxide based NPs.[9, 11] ICP-AES data revealed that some spleen accumulation of Fe occurred after the injection of
RGD-modified $\mathrm{T}_{1}-\mathrm{Fe}_{3} \mathrm{O}_{4}$ while only a tiny amount of Fe was absorbed by other organs (e.g., heart and lung). Comparing with the similar NPs in the literature,[27] significantly less $\mathrm{Fe}$ accumulated in liver parenchyma, which was in good agreement with the MRI and Prussian blue staining results. More importantly, Fe concentration in the tumors of mice injected with the RGD-modified NPs was much higher than that injected with the non-active-target NPs $(p<0.05)$. These results fully demonstrated the important roles of dense PEGylation and RGD targeting, which endowed RGD-modified $\mathrm{T}_{1}-\mathrm{Fe}_{3} \mathrm{O}_{4}$ with prolonged blood circulation, strong resistance to liver uptake, more effective delivery to hepatic tumors, and consequently allowed for the efficient detection of tiny hepatic tumors from the surrounding normal liver tissue through $\mathrm{T}_{1}$-weighted MR imaging.

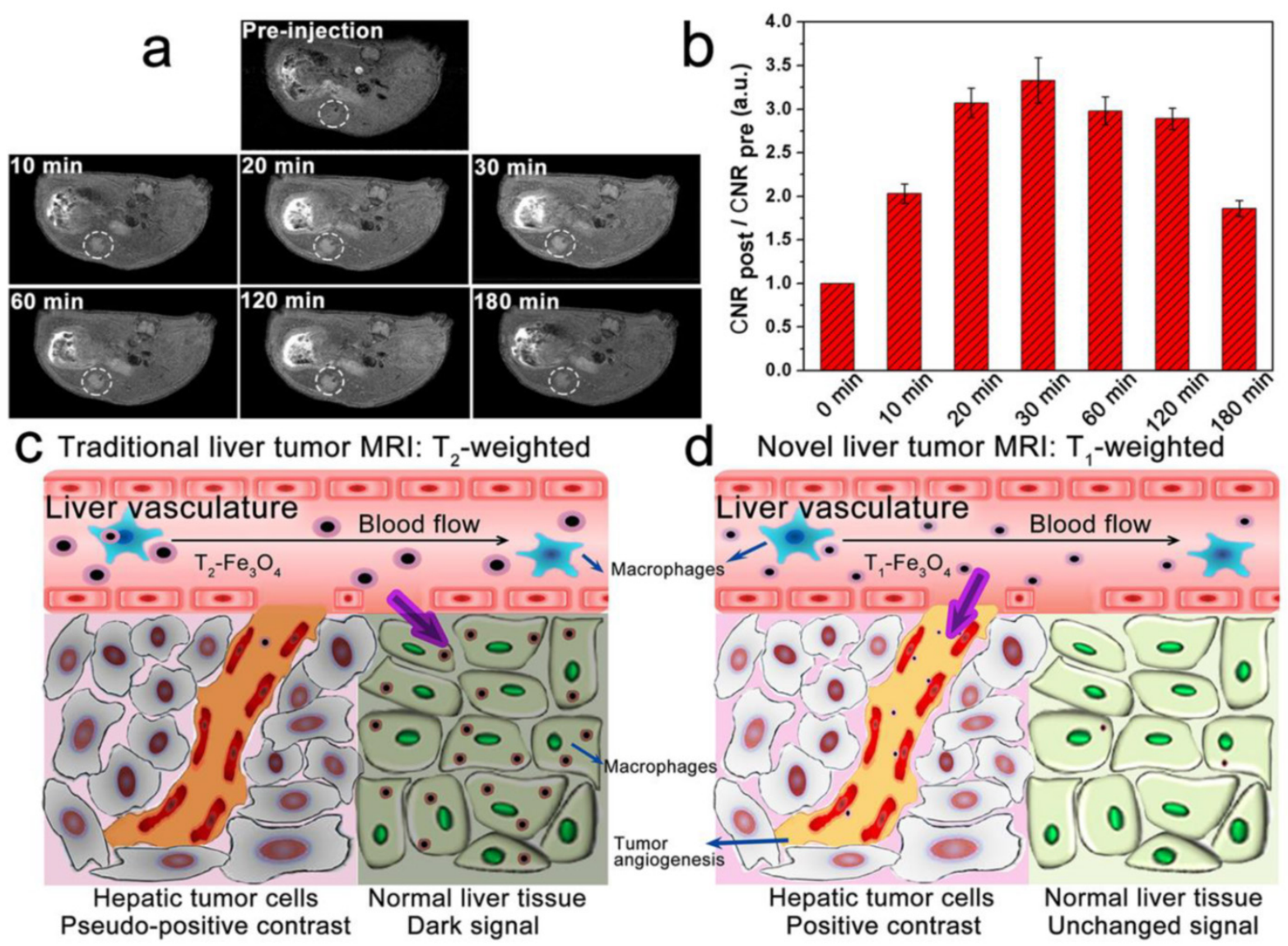

Figure 5. (a) $\mathrm{T}_{1}$-weighted MR images of mice bearing orthotopic hepatic tumor (white dashed circles) before and at the time points of $10,20,30,60,120$ and 180 min after the administration of RGD-modified $\mathrm{T}_{1}-\mathrm{Fe}_{3} \mathrm{O}_{4}$. (b) Quantification of $\mathrm{T}_{1}$ signal changes of tumor-to-liver CNR at the corresponding time points. The error bars represented \pm s.d. of three independent experiments. Hepatic tumors were differentiated from normal liver tissue through (c) pseudo-positive contrast effects by using traditional $\mathrm{T}_{2}-\mathrm{Fe}_{3} \mathrm{O}_{4}$ or (d) positive contrast enhancement by using novel tumor-target RGD-modified $\mathrm{T}_{1}-\mathrm{Fe}_{3} \mathrm{O}_{4}$. 

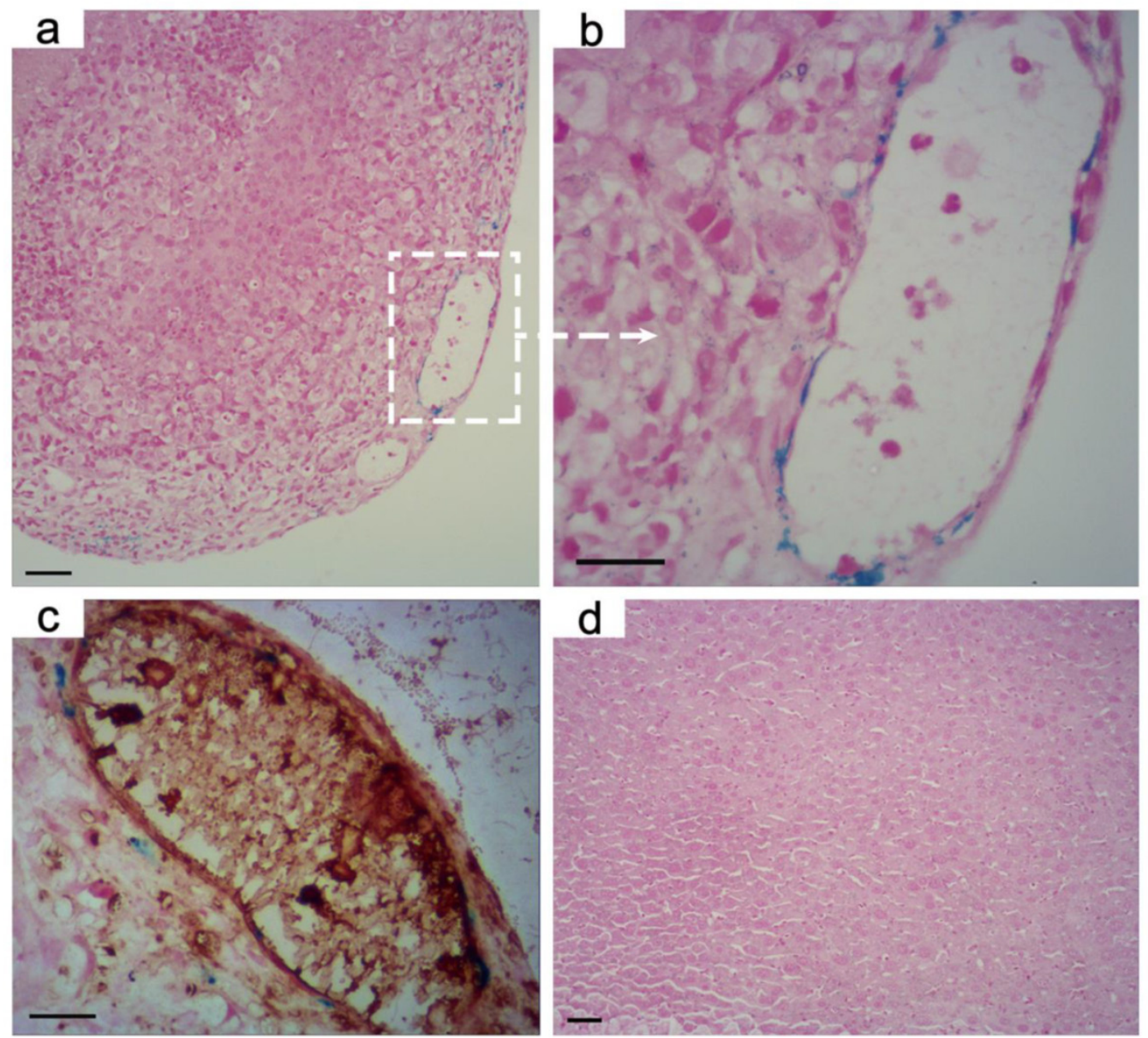

Figure 6. Prussian blue stained images of orthotopic hepatic tumor at the magnifications of (a) 200, (b) 400 after the administration of RGD-modified T/-Fe3 $\mathrm{O}_{4}$. (c) Overlay of Prussian blue and CD31 on the corresponding tumor slice in (b). Tumor angiogenesis were stained with brown. (d) Prussian blue stained image of normal liver tissue after the administration of RGD-modified $\mathrm{T}_{1}-\mathrm{Fe}_{3} \mathrm{O}_{4}$. It could be observed that $\mathrm{RGD}$-modified $\mathrm{T}_{1}-\mathrm{Fe}_{3} \mathrm{O}_{4}$ mainly accumulated in tumor angiogenesis with little phagocytosis by normal liver tissue which contains a great quantity of activated macrophages. Scale bar: $20 \mu \mathrm{m}$ for all images.
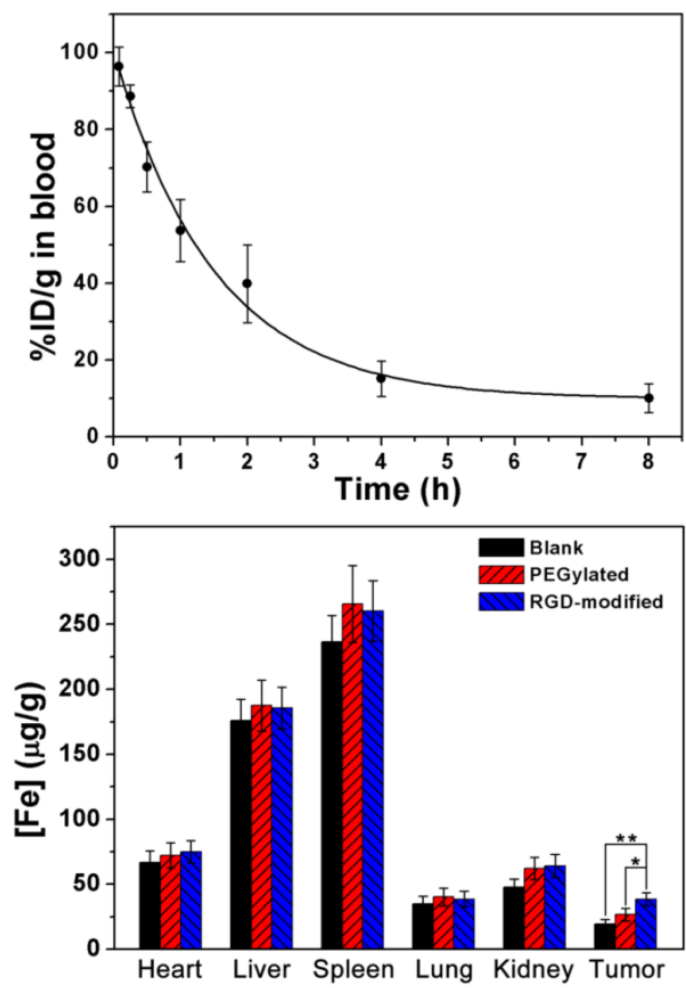

Figure 7. (a) Blood clearance profile of RGD-modified $\mathrm{T}_{1}-\mathrm{Fe}_{3} \mathrm{O}_{4}$ in mice $(n=6)$. The solid line was theoretical fitting curve depicting the clearance behavior. (b) In vivo biodistribution of $\mathrm{Fe}$ in some major organs (e.g., heart, liver, spleen, lung and kidney) and in hepatic tumor at $5 \mathrm{~h}$ after the administration of PEGylated $\mathrm{T}_{1}-\mathrm{Fe}_{3} \mathrm{O}_{4}$ or RGD-modified $\mathrm{T}_{1}-\mathrm{Fe}_{3} \mathrm{O}_{4}(5.0 \mathrm{mg} \mathrm{Fe} / \mathrm{kg})$. The error bars represented \pm s.d. of three independent experiments $(*, p<0.05 ; * *, p<0.01)$.

\section{Conclusions}

In summary, we have successfully developed a novel strategy for the efficient active-target imaging of hepatic tumors by using $\mathrm{T}_{1}-\mathrm{Fe}_{3} \mathrm{O}_{4}$ conjugated with $\mathrm{c}(\mathrm{RGDyK})$. The bioconjugation reaction was well-controlled and RGD-modified $\mathrm{T}_{1}-\mathrm{Fe}_{3} \mathrm{O}_{4}$ possessed relatively high $\mathrm{r}_{1}$ of $7.74 \mathrm{mM}^{-1} \mathrm{~s}^{-1}$ and ultralow $\mathrm{r}_{2} / \mathrm{r}_{1}$ ratio of 2.8 . Systematic stability studies revealed that $\mathrm{RGD}$-modified $\mathrm{T}_{1}-\mathrm{Fe}_{3} \mathrm{O}_{4}$ could be stored as monodispersed colloid in water for 15 months with quite little changes in $\mathrm{D}_{\mathrm{H}}$ or relaxation properties. Moreover, the targeting specificity to integrin $\alpha_{v} \beta_{3}$ could be kept as long as 15 months. Dense PEG 
coating endowed RGD-modified $\mathrm{T}_{1}-\mathrm{Fe}_{3} \mathrm{O}_{4}$ with favorable biocompatibility and strong ability to resist against the non-specific phagocytosis. Quite outstandingly, the intravenous administrated RGD-modified $\mathrm{T}_{1}-\mathrm{Fe}_{3} \mathrm{O}_{4}$ could significantly improve the diagnostic sensitivity and made it possible to clearly identify orthotopic hepatic tumor as small as $2.2 \mathrm{~mm}$ through active-target $\mathrm{T}_{1}$-weighted $\mathrm{MR}$ imaging, which has been recognized as one enormous challenge for hepatic tumor detection so far. Therefore, we believe that RGD-modified $\mathrm{T}_{1}-\mathrm{Fe}_{3} \mathrm{O}_{4}$ have much promising applications as highly sensitive positive contrast agent for MR imaging of various diseases with ongoing angiogenesis, especially for the accurate and early detection of liver cancer in patients.

\section{Supplementary Material}

Figures S1-S13.

http://www.thno.org/v06p1780s1.pdf

\section{Acknowledgements}

This work was supported by the National Key Basic Research Program of China (2013CB733800 and 2011CB933503), National Natural Science Foundation of China (31170959 and 81571806), the Basic Research Program of Jiangsu Province (BK2011036), the Jiangsu Provincial Technical Innovation Fund for Scientific and Technological Enterprises (SBC201310643) and the Jiangsu Provincial Special Program of Medical Science (BL2013029). The authors thank Dr. Jun-Jie Yin for his help and good comments concerning improvements to this work.

\section{Competing Interests}

The authors have declared that no competing interest exists.

\section{References}

1. Schroeder A, Heller DA, Winslow MM, Dahlman JE, Pratt GW, Langer R, et al. Treating metastatic cancer with nanotechnology. Nat Rev Cancer. 2012; 12: 39-50.

2. Torre LA, Bray F, Siegel RL, Ferlay J, Lortet-Tieulent J, Jemal A. Global cancer statistics, 2012. Ca-cancer J Clin. 2015; 65: 87-108.

3. Kumano S, Murakami T, Kim T, Hori M, Okada A, Sugiura T, et al. Using superparamagnetic iron oxide-enhanced MRI to differentiate metastatic hepatic tumors and nonsolid benign lesions. AJR Am J Roentgenol. 2003; 181: 1335-9.

4. Liu C, Gao Z, Zeng J, Hou Y, Fang F, Li Y, et al. Magnetic/upconversion fluorescent NaGdF4:Yb,Er nanoparticle-based dual-modal molecular probes for imaging tiny tumors in vivo. Acs Nano. 2013; 7: 7227-40.

5. Zhou Z, Huang D, Bao J, Chen Q, Liu G, Chen Z, et al. A synergistically enhanced $T_{1}-T_{2}$ dual-modal contrast agent. Adv Mater. 2012; 24: 6223-8.

6. Bellin MF, Zaim S, Auberton E, Sarfati G, Duron JJ, Khayat D, et al. Liver metastases: safety and efficacy of detection with superparamagnetic iron oxide in MR imaging. Radiology. 1994; 193: 657-63.

7. Zhao Z, Zhou Z, Bao J, Wang Z, Hu J, Chi X, et al. Octapod iron oxide nanoparticles as high-performance $T_{2}$ contrast agents for magnetic resonance imaging. Nat Commun. 2013; 4: 1161-71.

8. Huang J, Bu L, Xie J, Chen K, Cheng Z, Li X, et al. Effects of nanoparticle size on cellular uptake and liver MRI with polyvinylpyrrolidone-coated iron oxide nanoparticles. ACS nano. 2010; 4: 7151-60.

9. Zhou Z, Wang L, Chi X, Bao J, Yang L, Zhao W, et al. Engineered iron-oxide-based nanoparticles as enhanced $T_{1}$ contrast agents for efficient tumor imaging. ACS nano. 2013; 7: 3287-96.
10. Sadauskas E, Wallin H, Stoltenberg M, Vogel U, Doering P, Larsen A, et al. Kupffer cells are central in the removal of nanoparticles from the organism. Part Fibre Toxicol. 2007; 4: 10.

11. Kim BH, Lee N, Kim H, An K, Park YI, Choi Y, et al. Large-scale synthesis of uniform and extremely small-sized iron oxide nanoparticles for high-resolution $T_{1}$ magnetic resonance imaging contrast agents. J Am Chem Soc. 2011; 133: 12624-31.

12. Sandiford L, Phinikaridou A, Protti A, Meszaros LK, Cui X, Yan Y, et al. Bisphosphonate-anchored pegylation and radiolabeling of superparamagnetic iron oxide: long-circulating nanoparticles for in vivo multimodal (T1 MRI-SPECT) imaging. Acs Nano. 2012; 7: 500-12

13. Taboada E, Rodríguez E, Roig A, Oró J, Roch A, Muller RN. Relaxometric and magnetic characterization of ultrasmall iron oxide nanoparticles with high magnetization. Evaluation as potential $T_{1}$ magnetic resonance imaging contrast agents for molecular imaging. Langmuir. 2007; 23: 4583-8.

14. Li Z, Yi PW, Sun Q, Lei H, Li Zhao H, Zhu ZH, et al. Ultrasmall water-soluble and biocompatible magnetic iron oxide nanoparticles as positive and negative dual contrast agents. Adv Funct Mater. 2012; 22: 2387-93.

15. Huang G, Li H, Chen J, Zhao Z, Yang L, Chi X, et al. Tunable $T_{1}$ and $T_{2}$ contrast abilities of manganese-engineered iron oxide nanoparticles through size control. Nanoscale. 2014; 6: 10404-12.

16. Longmire M, Choyke PL, Kobayashi H. Clearance properties of nano-sized particles and molecules as imaging agents: considerations and caveats. Nanomedicine. 2008; 3: 703-17.

17. Perez JM, Josephson L, Weissleder R. Use of magnetic nanoparticles as nanosensors to probe for molecular interactions. Chembiochem. 2004; 5: 261-4.

18. Roch A, Gossuin Y, Muller RN, Gillis P. Superparamagnetic colloid suspensions: water magnetic relaxation and clustering. J Magn Magn Mater. 2005; 293: 532-9.

19. Lee N, Choi Y, Lee Y, Park M, Moon WK, Choi SH, et al. Water-Dispersible Ferrimagnetic Iron Oxide Nanocubes with Extremely High $\mathrm{r}_{2}$ Relaxivity for Highly Sensitive in Vivo MRI of Tumors. Nano Lett. 2012; 12: 3127-31.

20. Danhier F, Feron O, Préat V. To exploit the tumor microenvironment: passive and active tumor targeting of nanocarriers for anti-cancer drug delivery. J Control Release. 2010; 148: 135-46.

21. Hanahan D, Weinberg RA. Hallmarks of cancer: the next generation. Cell. 2011; 144: 646-74.

22. Carmeliet P, Jain RK. Angiogenesis in cancer and other diseases. Nature. 2000; 407: 249-57.

23. Brooks PC, Clark R, Cheresh DA. Requirement of vascular integrin $\alpha_{v} \beta_{3}$ for angiogenesis. Science. 1994; 264: 569-71.

24. Friedlander M, Theesfeld CL, Sugita M, Fruttiger M, Thomas MA, Chang S, et al. Involvement of integrins $\alpha_{v} \beta_{3}$ and $\alpha_{v} \beta_{5}$ in ocular neovascular diseases. Proc Natl Acad Sci USA. 1996; 93: 9764-9.

25. Dechantsreiter MA, Planker E, Mathä B, Lohof E, Hölzemann G, Jonczyk A, et al. $N$-Methylated cyclic RGD peptides as highly active and selective $\alpha_{v} \beta_{3}$ integrin antagonists. J Med Chem. 1999; 42: 3033-40.

26. Liu D, Wu W, Ling J, Wen S, Gu N, Zhang X. Effective PEGylation of iron oxide nanoparticles for high performance in vivo cancer imaging. Adv Funct Mater. 2011; 21: 1498-504.

27. Luo Y, Yang J, Yan Y, Li J, Shen M, Zhang G, et al. RGD-functionalized ultrasmall iron oxide nanoparticles for targeted $T_{1}$-weighted MR imaging of gliomas. Nanoscale. 2015; 7: 14538-46.

28. Tromsdorf UI, Bruns OT, Salmen SC, Beisiegel U, Weller H. A highly effective, nontoxic $T_{1}$ MR contrast agent based on ultrasmall PEGylated iron oxide nanoparticles. Nano Lett. 2009; 9: 4434-40.

29. Li S-D, Huang L. Pharmacokinetics and biodistribution of nanoparticles. Mol Pharm. 2008; 5: 496-504.

30. Walkey CD, Olsen JB, Guo H, Emili A, Chan WC. Nanoparticle size and surface chemistry determine serum protein adsorption and macrophage uptake. J Am Chem Soc. 2012; 134: 2139-47.

31. Liu C, Hou Y, Gao M. Are rare-earth nanoparticles suitable for in vivo applications? Adv Mater. 2014; 26: 6922-32.

32. Xie J, Zhang Y, Yan C, Song L, Wen S, Zang F, et al. High-performance PEGylated $\mathrm{Mn}-\mathrm{Zn}$ ferrite nanocrystals as a passive-targeted agent for magnetically induced cancer theranostics. Biomaterials. 2014; 35: 9126-36.

33. Zhang C, Jugold M, Woenne EC, Lammers T, Morgenstern B, Mueller MM, et al. Specific targeting of tumor angiogenesis by RGD-conjugated ultrasmall superparamagnetic iron oxide particles using a clinical 1.5-T magnetic resonance scanner. Cancer Res. 2007; 67: 1555-62.

34. Teicher BA. Tumor models for efficacy determination. Mol Cancer Ther. 2006; 5: 571-85. 